\title{
Pediatric mechanical circulatory support: A new era of "using the right tools, for the right job, at the right time"
}

\author{
Kyle W. Riggs, MD, and David L. S. Morales, MD
}

\footnotetext{
From the Department of Cardiothoracic Surgery, Cincinnati Children's Hospital Medical Center, Cincinnati, Ohio.

Disclosures: Dr Morales has the following disclosures: Syncardia, Inc-consultant, instructor, and clinical proctor), National Principal Investigator for the 50/50 cc Syncardia Total Artificial Heart FDA trial. HeartWare, Inc - consultant. Berlin Heart, Inc-instructor, consultant, and advisor. Oregon Heart-member of Medical Advisory Board. Dr Riggs has nothing to disclose with regard to commercial support.

Received for publication Dec 4, 2017; accepted for publication Dec 13, 2017; available ahead of print Jan 26, 2018.

Address for reprints: Kyle W. Riggs, MD, 3333 Burnet Ave, Cincinnati, OH 45229 (E-mail: kyle.riggs@cchmc. org).

J Thorac Cardiovasc Surg 2018;155:e165

$0022-5223 / \$ 36.00$

Copyright (c) 2017 by The American Association for Thoracic Surgery

https://doi.org/10.1016/j.jtcvs.2017.12.051
}

We applaud the innovative work and resilience highlighted in this case report by Woods and colleagues, ${ }^{1}$ as they effectively used the full armamentarium of mechanical circulatory support available for a child. There are multiple points worth emphasizing in this unique case. First, the use of the HeartWare HVAD System (HeartWare, Framingham, Mass) in a 13-kg child is noteworthy. There is growing evidence that the use of HVAD in children with a body surface area $<1 \mathrm{~m}^{2}$ can be successful, ${ }^{2}$ but there have been issues with stroke and thrombosis. Therefore, most in the field would say it is not yet known that children with a body surface area $<1 \mathrm{~m}^{2}$ can be consistently supported by the HVAD with acceptable outcomes. This case report does not shed light on this issue, since the support time was only 9 days. The decision to do a mitral valve repair and papillary sling is in line with a trend in the adult field to repair or even replace the mitral valve in patients with a ventricular assist device (VAD) with mitral regurgitation. Many feel that chronic mitral regurgitation may play a role in late right heart failure, especially in destination patients or patients in whom recovery is a possibility. However, in a patient who is being bridged to transplantation immediately, it is unclear that the increased risk of clot formation from pledgettes, etc, and increased crossclamp time is outweighed by a competent valve. One may wonder whether mitral valve repair was necessary in the setting of a continuous-flow VAD since atrioventricular valve excision is not infrequently performed in pediatric patients to allow VAD placement with good outcomes. Next, the authors' technique of continuous-flow VAD placement in a subrectus pocket stabilized by large suture placed around the device and through the rectus fascia was critical in allowing the VAD to fit intracorporeally.

Lastly, when the need for continued mechanical circulatory support became apparent after extracorporeal cardiopulmonary resuscitation (ECPR) on posttransplant day 21, patient.

\section{References}

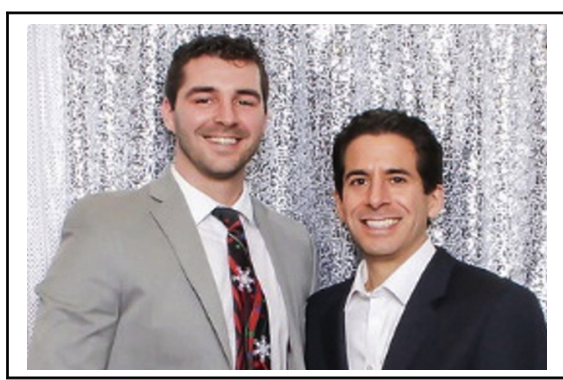

Dr Kyle W. Riggs, MD (left), and Dr David L. S. Morales, MD (right).

\section{Central Message}

With the ever-growing number of pediatric mechanical circulatory support devices, one must be aware of all the devices available and conscientious about using the correct tool for the correct job.

See Article page e161.

the transition from extracorporeal membrane oxygenation (ECMO) to temporary VAD was the appropriate decision and well-timed after 4 days of ECMO support. Currently, ECMO continues to be used far too frequently when only cardiac support is needed. After the appropriate use of ECMO for ECPR, the team realized the lungs were not an issue and appropriately removed the oxygenator (significant source of inflammation, hemolysis, etc) and converted to a temporary VAD. Furthermore, their conversion of inflow from the neck to the left ventricular apex through a left minithoracotomy with limited rib resection exemplified another creative modification to provide VAD support in a small patient. Avoidance of another repeat sternotomy with this technique likely helped the recovery of this child after multiple previous surgeries. Overall, the use of ECMO as ECPR, temporary VAD, long-term VAD, and cardiac transplantation in this report represents an excellent use of the correct tools at the correct time in a complex pediatric

1. Woods RK, Neibler RA, Kindel SJ, Mitchell ME, Tweddell JS, Hraska V. Multiple mechanical support modalities and cardiac transplantation in a young child with corrected transposition. J Thorac Cardiovasc Surg. 2018;155:e159-61.

2. Miera O, Kirk R, Buchholz H, Schmitt KR, Rebeyka I, Wrightson N, et al. Multicenter review of Heartware ventricular assist device in small children. J Heart Lung Transplant. 2015;34:S328-9. 